\title{
Robotic Spraying Application for Fabrication Proton Exchange Membrane Fuel Cell
}

\author{
Ramli Sitanggang* \\ Program Studi Teknik Kimia UPN “Veteran” Yogyakarta, \\ Jl SWK 104 Condongcatur, Yogyakarta, 55283
}

\section{Artikel histori : \\ Diterima September 2016 Diterima dalam revisi Oktober 2016 Diterima November 2016 Online Juni 2017}

\begin{abstract}
One of the processes that work in the field of engineering Proton Exchange Membrane Fuel Cell (PEMFC) is to produce a variety of designs MEA. The best design will be found in the manufacturing process. The project introduced a spray with a robotic instrument configuration $\mathrm{x}-\mathrm{y}$ axis to issue MEA design. MEA layer forms which can be produced by this spray will follow a periodic function, whereas the layers including the thickness, porosity, pore diameter, specific active surface area which will be used to hold the chemical reaction to produce electricity. The character size coating layer is represented by the amount of spraying. This number is a function of the frequency of the robot, and the nozzle crosses the $x-y$ dimensions of the substrate. Sprays produce two forms of MEA design. From the results of this study MEA quality can be assessed using a robot with a spray nozzle configuration as a contribution for Fuel Cell (PEMFC).
\end{abstract}

Keywords: Sprayer; MEA design; Fabrication; Fuel cell

\section{Introduction}

One of the working processes in engineering of MEA is to manufacture various designs. Among those designs were found the best one and being manufactured. In manufacturing PEMFC there are eleven layers involved with the desain and manufacturing. The sequence of those layers is the bipolar plate (BP), gas flow field (FF), gasket $(\mathrm{G})$, gas diffusion layer (GDL), electrode (E), membrane (M). This layer configuration is the BP-FF-G-GDL-E-ME-GDL-G-FF-PP. The electrode assembly (MEA) part has 5 layers of GDL-E-M-E-GDL and recently was develop as 6 layers and called MEGA or G-GDL-E-M-E-GDL-G. Design and manufacturing of gas flow field PEMFC have fast growing development and manufacturing using CNC instrument. The MEA design begins to develop continuously to improve the performance of PEMFC. One of the basic principles to design MEA is to use nanotechnology so as to employ a very sensitive instrument such as vacuum plasma spray coating, vacuum atomization and sputtering.

Many simulations and experimental MEA previously undertaken to guide the explanation of layer size of the MEA in fuel cell and always to be developed by the more accurate equation (Ramli Sitanggang et.al, 2009). Layer size of MEA and the interdependence between sizes is performed by graphics and the performance equation of PEM fuel cell (Iyuke, et.al, 2003; Gurau et.al, 2002; Guang Z, et.al, 2000). From the mapping simulation and experimental results were carried out, these are the thickness, porosity, pore diameter activated specific surface area are the very crucial parameters of MEA (Siegel, 2003; Paganin et.al, 1996; Nam J.H and Kayianti M., 2003; Hsin-Sen Chu et.al, 2003), and are expressed by the equation related to voltage and PEM fuel cell current (Tianhong Zhou and Hongtan Liu, 2001; C.S.Kong et.al, 2002; Lixing You and Hongtan Liu, 2001). The thickness of the catalytic layer must be able to conduct protons and their reactions (Gurau V, et.al, 2002; Andrew Rowe and Xianguo Li, 2001; Shan Hai et.al, 2003). High active surface area catalyst is also essential to conduct an enough high reaction rate (Hsin-Sen Chu et.al, 2003) . Besides that, the effective porosity will increase the current density of the PEM fuel cell flow (C.S Kong et.al, 2002). Maximizing the current density is often carried out by adjusting the thickness and effective porosity to create uniform distribution of gas and humidity in MEA (Gurau,V et.al, 2002; Huang Z ，2000). Generally, electrode sizes are optimized on the requirement of the transfer of the mass, electrons, protons, and completing the ionic reaction on the electrode (MEA (Siegel, 2003; Paganin et.al, 1996; Nam J.H and Kayianti M., 2003). It seems that the best solution is to minimize the thickness of the catalyst layer while optimizing the combination of the electrode size parameters (Tianhong Zhou and Hongtan Liu, 2001; C.S.Kong et.al, 2002; Lixing You and Hongtan Liu, 2001). The layers preparation includes involves ink, coating, pressing and drying (Ramli Sitanggang et.al, 2009; Iyuke, et.al, 2003; Siegel, 2003). In general, the layers preparation of MEA have to be carried out by utilizing the ink coating method on the surface of gas

*Corresponding Author:

Email: ramlisitanggang@yahoo.com 
diffusion electrode (GDE) or above the membrane surface (Siegel, 2003). One of the equipments required to perform the experiment is a spraying method. In this research the equipment used is Robotic Nozzle Sprayer which is able to conduct the uniform ink mixing with high tubulence. Besides that, it has a function as ink distributor to the surface of substrate. The objective of this research is to study the control of layers fabricating using robotic characteristic numbers with typical nozzle konfiguration as a contribution to do the design GDE and to determine electrode layer of MEA. Characterization, Benchmarking polarization of PEM fuel cell.

\section{Theory}

\subsection{X-y Robotic Spraying}

The robot used in the system employs a specific attitude expression of the $x-y$ configuration shown in Fig $1 b$.

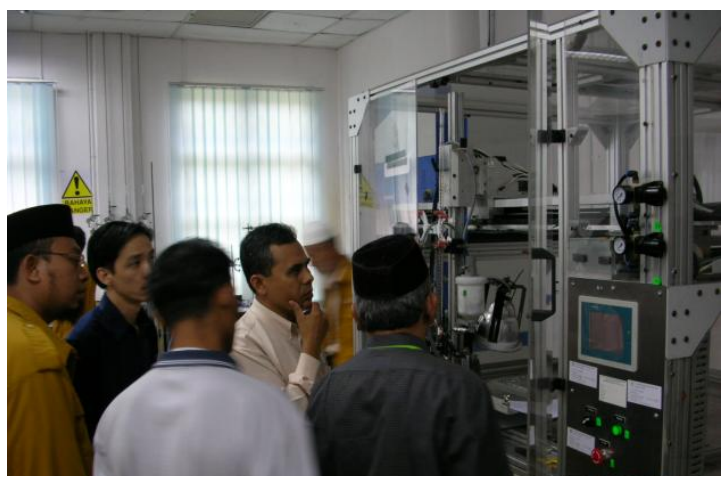

a.

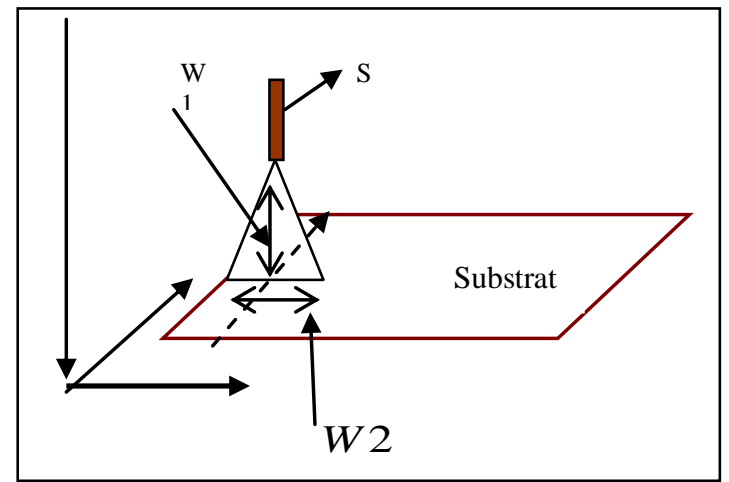

b.

Figure 1.(a) x-y Robotic Spraying, (b) The $x-y$ configuration

The spray variable is expressed by frequency $(\omega)$, nozzle height $\left(\mathrm{W}_{1}\right)$, distribution distance $\left(\mathrm{W}_{2}\right)$, division number of spray coating line on substrate (n) and nozzle velocity (S) (M. Grujicic and K.M Chittajallu, 2004). The spray direction coating process is designed perpendicular to substrate. The nozzle frequency is given by equation 1 . $\omega=\frac{n S}{2(n y+x)}$

In equation 1, the robotic frequency depends on $S$ and $N$ at certain boundary condition.. If the nozzle height $W_{l}$ is direct proportional to $\Delta x$ and $W_{l}$ is designed to be proportional with $W_{2}$. Assumed the $N_{\text {spray }}$ is known as the characteristic number of robotic spray, therefore the calculated value will be determined as follows based on the passing sprayer movement:

$N_{\text {spray }}=\frac{S-2 \omega S y}{2 \omega W_{1}}$

Based on the equation 2, CAD is designed to possess the dimensions of $x, y, n, S$ and $W_{l}$ level.

The nozzle position on $\mathrm{x}-\mathrm{y}$ axis is generated on the CAD system according to parameter $\mathrm{n}$. The spray coating consists of the nozzle position and control code. The control code has a value corresponding to the desired substrate condition.

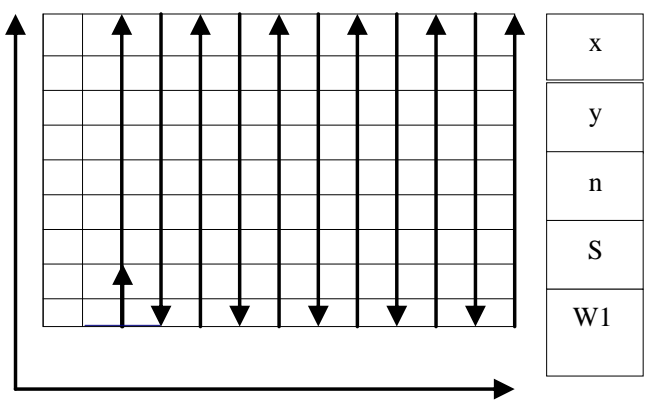

Figure 2. CAD of workpiece

\subsection{Performance x-y Robotic Spraying}

The variable of ink drop distribution of the nozzle will affect the layer size are ${ }^{\mu}, v$ and $p$.

$t_{e}, d_{p,} \varepsilon, a_{s}=f(K, \mu, v, \sigma, p)$

With thick size $\left({ }^{t_{e}}\right)$, pore diameter $\left(d_{p}\right)$, porosity $(\varepsilon)$, typical activated specific surface $\left(a_{s}\right)$.

Assume $p$ is constant, surface tension $(\sigma)$ constant, thus theoretically the correlation of $t_{e}, d_{p}, \varepsilon$, and $a_{s}$ toward all variables and the robotic movement as well as the drop variable are given by dimensionless equation 4

$t_{e}, d_{p,} \varepsilon, a_{s}=f\left(N_{\text {spray }}, \operatorname{Re}, W\right)$

The viscosity effect and surface tension are constant and neglecting the solidifying effect on substrate surface. Based on equation 3 , the $t_{e}, d_{p}, \varepsilon, a_{s}$ are given by the dimensionless equation 4 to 5 , as follows :

$t_{e}, d_{p,} \varepsilon, a_{s}=f\left(N_{\text {spray }}\right)$ 
Equations 4 to 5 , the $t_{e}, d_{p}, \varepsilon$ and $a_{s}$ of an electrode can be determined by the robotic characteristic number $\left(N_{\text {spray }}\right)$. Assumed the layers results from robotic sprayer is set to be the MEA, therefore the relationship of $N_{\text {spray }}$ with the current density of PEM fuel cell can be formulated using Grujicic (2004) (E.Guzlow and T. Kaz, 2002). The spraying technique model for MEA fabrication is as follows:

\section{Current density (i):}

$$
\begin{aligned}
& i=K_{4} C_{O 2}\left(1-\left(K_{5} \exp \left(-K_{6}\left(\phi_{s}\right)\right)^{1 / 2}\right)\right. \\
& x \operatorname{coth}\left(K_{5} \exp \left(-K_{6}\left(\varphi_{s}\right)\right)\right)^{1 / 2} \\
& K_{4}=\frac{12 t_{e}(1-\varepsilon) F D_{O 2}}{0.5 d_{p}}=f\left(N_{\text {spray }}\right) \\
& K_{5}=\frac{i_{0, c} a_{s 1}\left(0.5 d_{p}\right)^{2}}{4 F C_{o 2}^{r e f} D_{O 2}}=f\left(N_{\text {spray }}\right)
\end{aligned}
$$

Voltage (V):

$$
\begin{aligned}
& V= \\
& E-\frac{R T}{0.5 F} \ln \left\{f _ { 1 } ( d p , \varepsilon ) C _ { O 2 } \left(1-\left(f_{1}(d p, \varepsilon)\right.\right.\right. \\
& \left.\frac{i_{0, c}}{C_{o 2}^{r e f}} \exp \left(-\frac{R T}{0.5 F}\left(\phi_{s}\right)\right)^{1 / 2}\right) x \\
& \left.\operatorname{coth}\left(f_{1}(d p, \varepsilon) \frac{i_{0, c}}{C_{o 2}^{r e f}} \exp \left(-\frac{R T}{0.5 F}\left(\varphi_{s}\right)\right)\right)^{1 / 2}\right) / i_{o, c}
\end{aligned}
$$

Based on equations, the value of coeffisient model of current density depend on $N_{\text {spray }}$. The $N_{\text {spray }}$ becomes the main control for manufacturing layer size of MEA design form.

\subsection{Fabrication MEA}

Generally, the MEA design form configuration employed by researches as shown in Fig.3a is the G-GDL-E-M-EGDL-G.
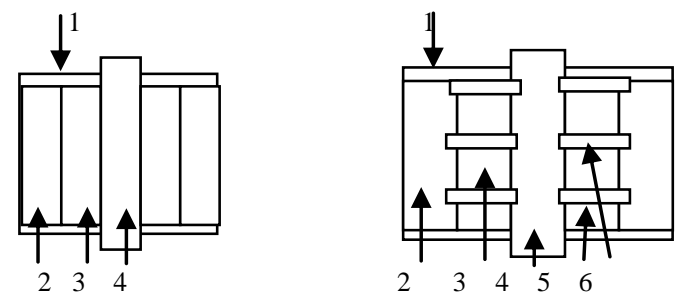

Figure.3. The MEA design configuration: (a) General MEA design, (b) New MEA design form. (1) Gasket, (2) GDL, (3) electrode, (4) membrane, (5) composite, (6) electrode support, (c) MEA
In this paper the catalyst layer employed the configuration as shown in Fig.3b to obtain highly activated specific surface area. In Fig.4 the catalyst utilised a support to composite the catalyst into the membrane (novel).

\section{Experiment}

Gas Diffusion Layer (GDL) in MEA employed Vulkan $\mathrm{XC}-72 \mathrm{R}$ carbon black with particle size 38 nanometer or aggregate 5 micron, PTFE $60 \%$ (w\%), prophyl alkohol 89 $\%$ and carbon cloth (S. Sakamoto, 1990) with a thickness of 210 micron. Vulcan XC-72 loading in GDL is as large as $5 \mathrm{mg} / \mathrm{cm} 2$ and PTFE $1.25 \mathrm{mg} / \mathrm{cm} 2$.

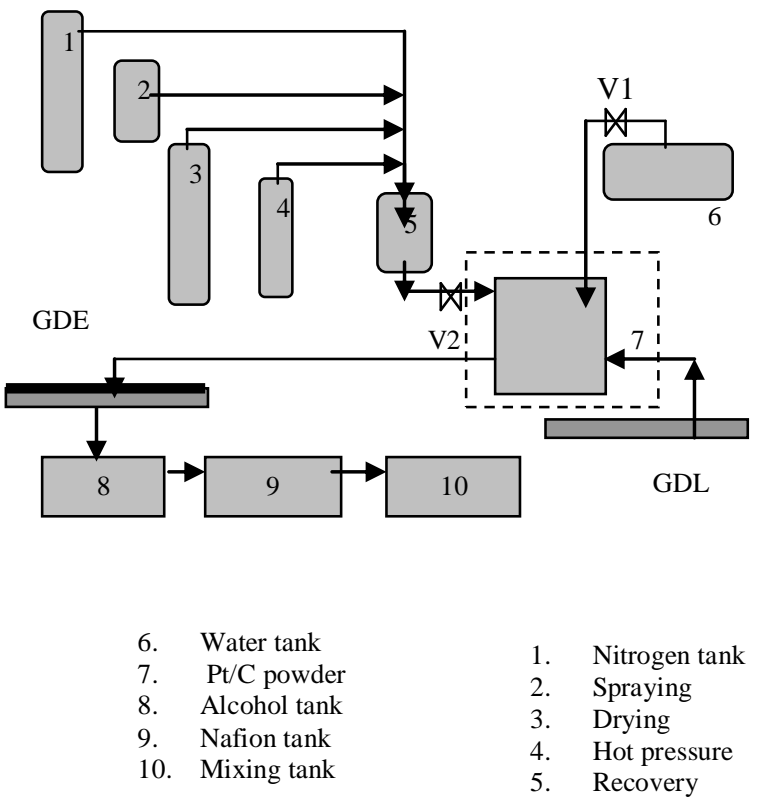

Figure. 4. The flow chart of MEA Fabrication

The electrode layer in MEA employed a mixture of $\mathrm{Pt} / \mathrm{C}(20 \%)$, nafion solution (5\%), prophyl alkohol $89 \%$ and water. The weight ratio of $\mathrm{Pt} / \mathrm{C}$ and Nafion in electrode ink was made to be $0.7: 0.3$ (G. Maggio et.al, 2001). The ratio of Nafion with water was made to be $1: 15$. To obtain a sprayer characteristic, Pt/C ink was spread over the GDL surface with $\mathrm{N}$ values of 0.5 to 2.0. The spraying pressure of air mixture was 4 bar. The spraying applied hot plate under $60{ }^{\circ} \mathrm{C}$ to remove isoprophyl alcohol.

The flow chart of spraying is shown in Fig. 4.9 with operational condition as follows : nozzle height 7 , hot plate under $60^{\circ} \mathrm{C}$, air compressor $4 \mathrm{~kg} / \mathrm{cm}^{2}$. The pattern of nozzle 7 is shown in Fig. 2. The mixing process in mixing tank 5 is set to be laminar.

The characteristic number of spraying is adjusted by PLC panel as desired. When the temperature of GDL achieved $60^{\circ} \mathrm{C}$, then the speed of ink catalyst is set as desired. At the same time, the robotic is set to be on. After spraying process, the substrate should be dried for $1 \mathrm{~h}$ and then put in the dryer under $80^{\circ} \mathrm{C}$ for $3 \mathrm{~h}$. Afterwards hot pressure should be undertaken for 3 minutes, under $130^{\circ} \mathrm{C}$ 
and pressure of $50 \mathrm{kgcm}^{-2}$. This kind of work has been done for various numbers of spraying characteristic. The next step, examinations have been carried out for thickness, holes, hole diameter, GDE surface area to obtain spraying data.

The technique of GDE fabrication has been adjusted to the available design as well as the technique for characterization. The work has been done after selecting spraying variables in the characterization work. The same method has been done for GDE fabrication. The GDE fabrication are shown in Fig. 3a and 3b. After finishing GDE fabrication, the Nafion 117 membrane is cleaned by 3 wt $\% \mathrm{H}_{2} \mathrm{O}_{2}$ under $80^{\circ} \mathrm{C}$ for 1 h to oxidize organic impurities. Impurities are removed by boiled water for $1 \mathrm{~h}$. To remove the expected inorganic in the membrane, the membrane should be cleaned by $\mathrm{H} 2 \mathrm{SO} 45 \mathrm{wt} \%$ under $80{ }^{\circ} \mathrm{C}$ for $1 \mathrm{~h}$. The membrane is washed by water under $80^{\circ} \mathrm{C}$ several times until really clean. Moreover, the layers are combined by configuration type of GDEA-M-GDEK. Hot pressing has been done under $50 \mathrm{~kg} / \mathrm{cm} 2$, at $130^{\circ} \mathrm{C}$ for 3 minutes. The result of this arrangement is called as MEA.

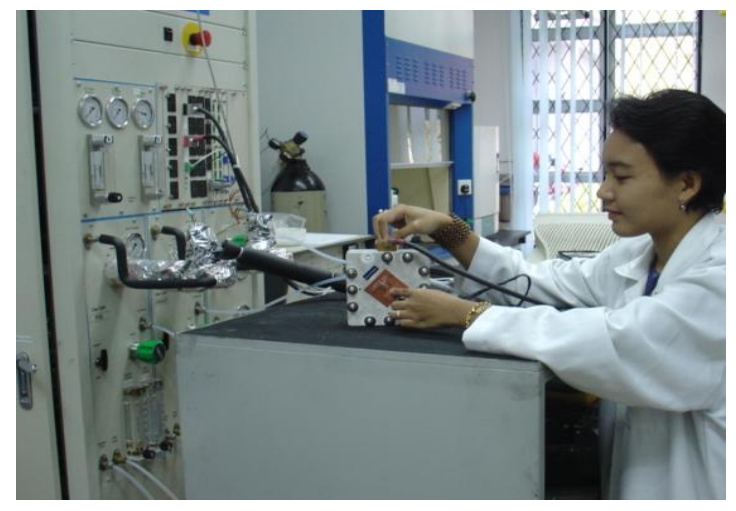

Figure 5. Instrumen Arbin

The instruments used for analysis to collect spraying data are the porosimeter and FCTS. Examination using porosimetry is employed for collecting data of holes, hole diameter and hole surface area. Furthermore, the layer is merged with the membrane as shown in the flow chart in Fig. 4. The MEA from hot pressing is examined by FCTS made of Arbin.

\section{Result and Discussion}

The research in MEA layer designing includes two steps i.e. the sprayer characteristic and MEA designing and manufacturing. The effect of spray ding on electrode layer size is demonstrated in Fig 7. From Fig 6 it will determine the electrode thickness on the surface of GDE. When we observe the distribution of data point there are many choice to determine electrode thickness which followed the method as described in journal. In this investigation, the robotic sprayer is adjusted to yield electrode thickness from $0.01 \mathrm{~mm}$ to $0.05 \mathrm{~mm}$ (G. Maggio et.al, 2001). The correlation of porosity, diameter pore and activated specific surface area with $\mathrm{N}$ is illustrated as exponential function.

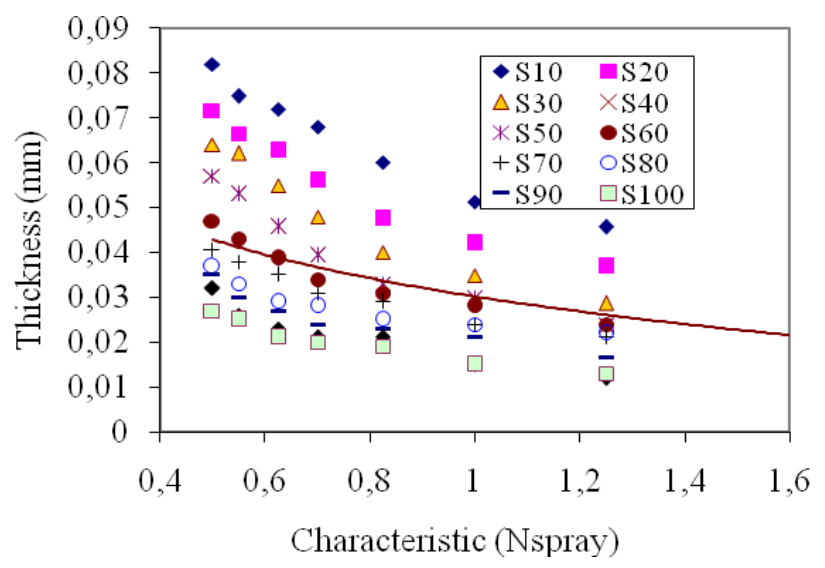

Figure 6. The effect of characteristic x-y Robotic spraying number on electrode thickness
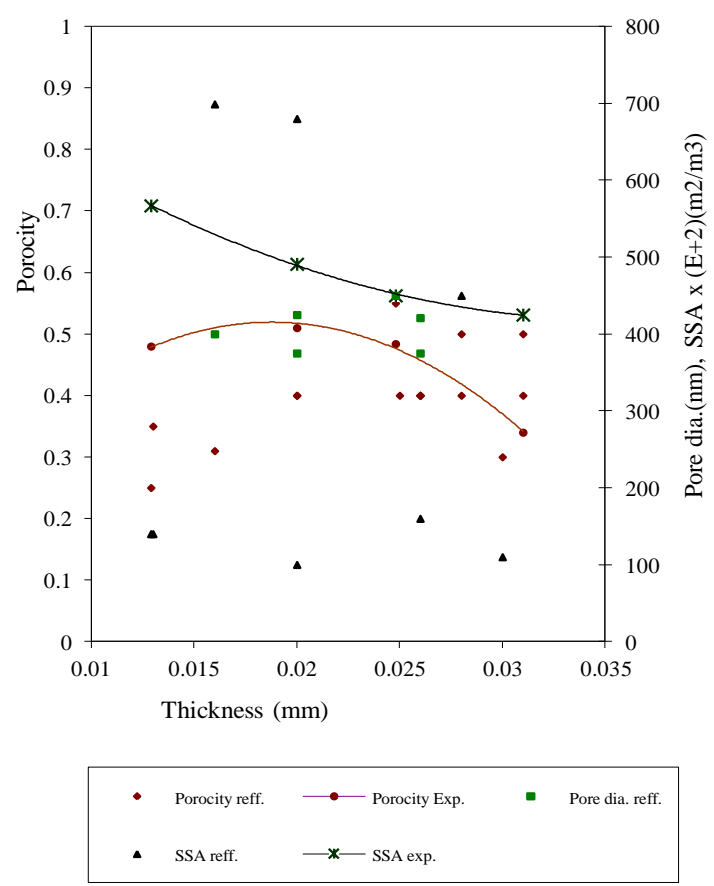

Figure 7. The mapping from sprayer result

For porosity, it has a coefficient of $2.57210^{-5}$ and power of -0.59 . For hole diameter, it has coefficient of $3.8710^{-7}$ and power of 0.23 , and for activated specific surface area it has coefficient of $3.8410^{5}$ and power of 0.094 . We obtain the interdependent of sizes, i.e. $t_{e}, \mathrm{~d}_{\mathrm{p}}, \varepsilon, \mathrm{a}_{\mathrm{s}}$ which one another will be related with values of $N_{\text {spray. }}$. The smaller the value of $\mathrm{t}_{\mathrm{e}}$ while $\mathrm{d}_{\mathrm{p}}, \varepsilon$ and $\mathrm{a}_{\mathrm{s}}$ will be larger. This condition indicated that when one of the sizes to be determined so the other size will be fixed. As so far the characteristic sprayer 
will only adjust the thickness and forms a layer followed MEA design.

The mapping from simulation modelling and experiment will show the thickness value of electrode $\left(t_{e}\right)$ of the PEM fuel cell $t_{e}$ that are from 10 to 35 micron (0.001-0.035 $\mathrm{cm}), \varepsilon$ from r 0.25 to 5 , size average, $d_{p}$ is $400 \mathrm{~nm}$ and $a_{s}$ are from 1100 to $6000 \mathrm{~cm}^{2} \mathrm{~cm}^{-3}$. It is found that some values from eq. are located on that mapping. This implies that the sprayer can follow the results of simulation and experiment in journals. For example, the mapping from sprayer result are demonstrated in Fig.8.

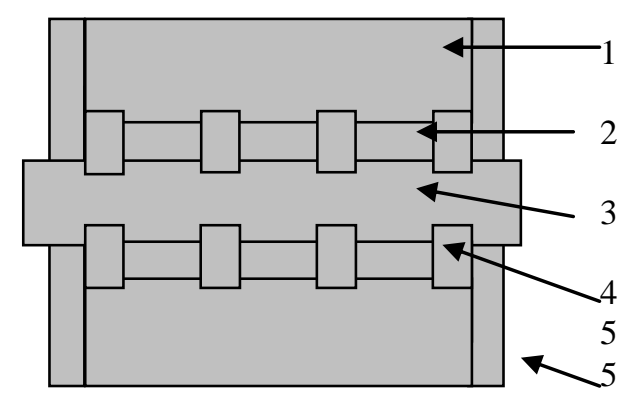

1. GDL 210 micron

2. Catalyst $=20$ micron

3. Membrane 180 micron

4. Electrode Support

5. Gasket 230 micron

Figure 8. The MEA design form

In this design, the experimental MEA starting point, $N_{\text {spray }}$ is to be 0.7 . and will yield the current density of PEMFC around $60 \mathrm{~mA} / \mathrm{cm} 2$. Afterwards the $N_{r s}$ is to be 1.0 , will produce current density of $85 \mathrm{~mA} / \mathrm{cm} 2$. In turn it implies that thinner electrode on GDL surface, the current density obtained becomes larger. The thickness of the catalytic layer got thinner will be able to conduct protons and their reactions (Gurau, $\mathrm{V}$ et. Al, 2002; Andrew Rowe and Xianguo Li, 2001; Shan-Hai Ge and Bao-Lian Yi, 2003). This is due to the higher active surface area catalyst obtained (Hsin-Sen, 2003). Besides that, the effective porosity will increase the current density of the PEMFC flow (C.S.Kong, 2002). By adjusting the $N_{r s}$, the thickness and porosity will produce uniform distribution of gas and humidity in MEA layers (Gurau,V, 2002; Huang Z., 2000). It seems that the best solution to minimize the thickness of the catalyst layer as done in this research is in agreement with previous journals (current (Tianhong Zhou and Hongtan Liu, 2001; C.S.Kong et.al, 2002; Lixing You and Hongtan Liu, 2001).

In manufacturing the electrode layers there is an improvement in current density as large as $41.6 \%$ from the experimental MEA starting point mentioned above. The increment is high enough therefore the $N_{\text {spray }}$ will be found to be 1 and used for manufacturing both for designing as is shown in Fig. 8 as well as other design.

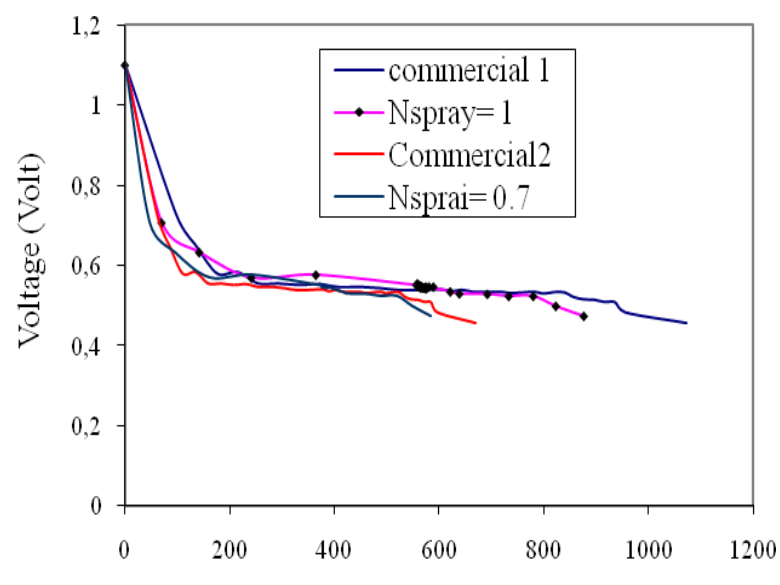

Current density $(\mathrm{A} / \mathrm{m} 2)$

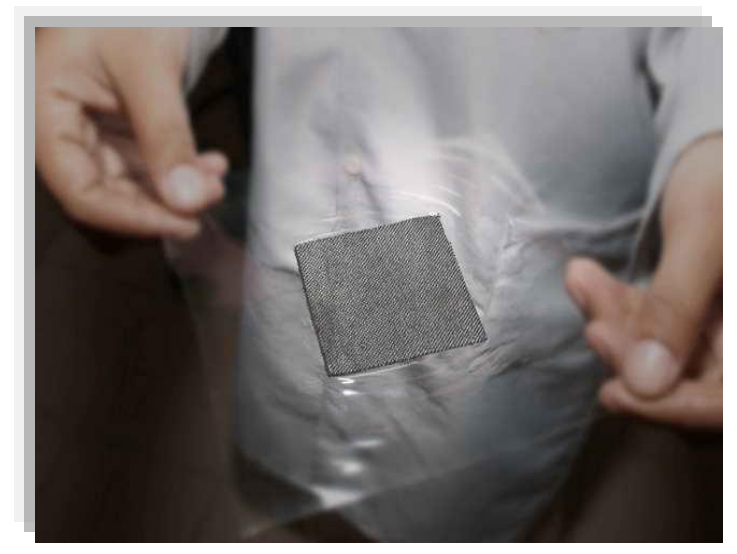

Figure 9. The polarization of PEM fuel cell

\section{Conclusion}

The sprayer in this experiment can produce different sizes of thickness, pore diameter, porosity and activated specific suface area. the size of the layer can be done with some features spray robot. Increasing the spray characteristics will result in improved performance of PEM fuel cells. From the experimental results, the value of $N$ is for unity and could make electrodes. Configuration layer on the substrate is a periodic function. The value of $\mathrm{N}$ is for unity and can be used as a method for manufacturing design MEA. 


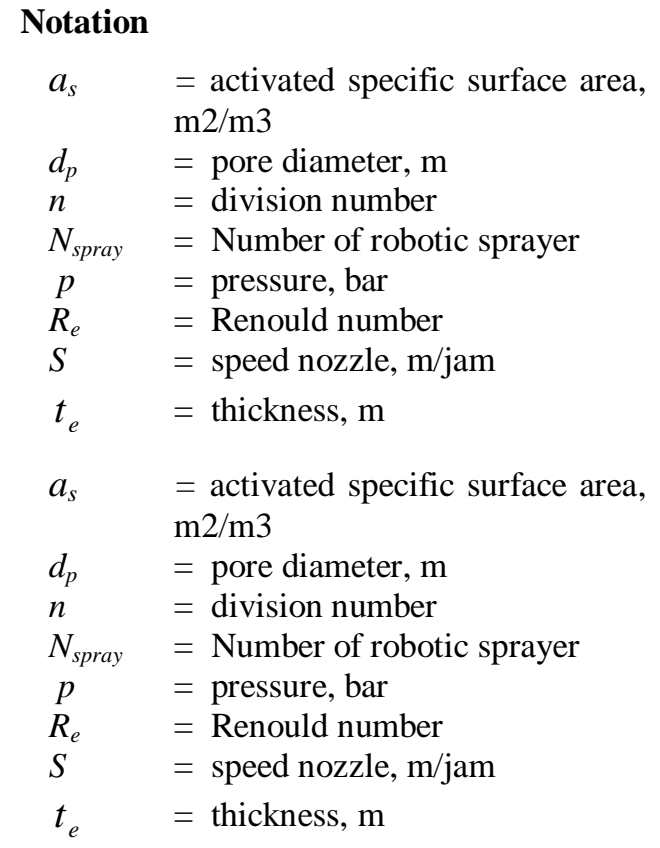

\section{References}

Andrew Rowe, Xianguo Li., 2001, Matematical modeling of Proton exchange membrane fuel cells., Journal of power sources, Vol 102, 82-96

C.S.Kong, D.Y Kim, H.K. Lee, Y.G. Shul, T.H. Lee, 2002, Influence of -pore size distribution of diffusion layer on mas- transport problem of proton excange membrane fuel cell, J. Power Sources, Vol 108, 185191

D. Singh, D.M. Lu, N. Djilahi,. 1999, A two-dimensional analysis of mass transport in proton exhange membrane fuel cells. International Journal of Enginering Science, Vol 37, 431-452

E.Gulzow, M.Schulze, N. Wagner, T. Kaz, R.Reissner, G.Steinhilber, A.Schneider, 2000, Dry layer preparation and characterisation of polymer electrolyte fuel cell components, Journal of power Sources 86, $352-362$

E.Guzlow, T. Kaz, 2002, New Result of PEMFC electrode pruduce by DLR dry preparation technique, J..Powre sources 106, 122-125

G. Maggio. V. Recupero, L. Pino, 2001, Modelling polymer electrolyte fuel Cell: an innovative approac., Journal of Power Source 101, 275-286

Gurau,V., Liu, H., and Kakac, S., 2002,Two-Dimensionnal Model for Proton Exchange Membrane Fuel Cells. Dept, of Mechanical Engineering, univercity of Miami. Coral Gables, Fl33124

Hsin-Sen Chu, Chung Yeh, Falin Chen, 2003, " Effects of porocity change of gas diffuser on performance of proton exchange membrane fuel cell. Journal of Power Sources 123, 1-9
Huang Z., 2000, Experiment and Matematical studies for PEM fuel Cell Performance, M.S. thesis, University Miami, coral gables, Florida.

Iyuke, S.E., Mohamad, A.B.,. Khadhum, A.A.H., Daud, W.R.W., Rachid, C., 2003, Inproved membrane and electrode assemblies for proton exchange membrane fuel cells. Journal of Power Source, Vol. 114,195-202

Litster S., McLean G.,2004, "PEM Fuel cell electrodes", Journal of Power Sources, inpress

Lixin You, Hongtan Liu, 2002, A two-phase flow and transport model for the cathode of PEM fuel Cell., International Journal of heat and mass transfer Vol 45, $2277-2287$

Lixing You, Hongtan Liu, 2001, Aparametric study of the chatode catalyst layer of PEM fuel Cell using a pseudo-homogenous model. International journal of hydrogen Energy, Vol 26, 991-999

M. Grujicic, K.M Chittajallu, 2004, Design and optimization of polymer electrolyte membrane (PEM) fuel cells, Applied Surface Sience inpress.

Moreira, J., Ocampo, A.L., Sebastian, P.J., Smith, A., Salazar, M.D., Del Angel, P., Montoya, J.A..Perez, R Martinez, L., 2003, Influence of the hydrophobic material content in the gas diffusion electrodes on the performance of a PEM fuel cell. International Journal of Hydrogen Energy Vol 28, 625-627

Nam.J,H.,Kavianti M., 2003, Effective diffusivity and water-saturation distribution in single- and two-layer PEMFC diffusion medium". Pergamon, International journal of mass transfer, Vol 46, 4595-4611

Nedjib Djilali, Dongming Lu, 2002, Influence of heat transfer on gas and water transport in fuel cell. Int.J. Therm. Sci. Vol 41, 29-40

P.C. Sui and L.-D Chen, James P.Seaba. Yoshinori Wariishi, 1999, Modelling and Optimation of a PEMFC Catalyst Layer. International Conggress and Exposition Detroit, Michigan

Paganin, V.A., Ticianelli, E.A., Gonzalez, E.R., 1996, Development and electrochemical studies of gas diffusion electrodes for polymer electrolyte fuel cell. J. Appl. Electrochem, 26297-304

Ramli Sitanggang, Mohamad A.B., Daud, W.R.W., Kadhum, A.A.H., Iyuke S.E, 2009, Fabrication of gas diffusion layer based on $\mathrm{x}-\mathrm{y}$ robotic spraying technique for proton exchange membrane fuel cell application, An Internatonal Journal, Energy Conversion and Management, Vol 50, 1419-1425

S. Sakamoto, 1990, Mechnical Planning and Actual Result of painting Robot for high rised building, Jof Robotics Society of Japan , *-2, pp. 229-233

Shan-Hai Ge, Bao-Lian Yi.,2003, A matematical model for PEMFC in different flow modes., Journal of Power Sources, impress. 
Siegel, Siegel P.N. 2003, A two-dimensional computasional model of PEMFC with liquid water transport. Journal of Power sources, inpress

Tianhong Zhou and Hongtan Liu, 2001, Ageneral Theredimensional Model For proton Exchange Membrane Fuel Cell. J.Transport phenomena, 3(3):177-198
Tien-Chien Jen, Tuanzhou Yan, Shih-Hung Chan., 2003, Chemical reacting transsport phenomena in PEM Fuel Cell. International Journal of Heat and Mass Transfer, Vol. 46, 4157-4168 